\title{
pACC1 peptide loaded chitosan nanoparticles induces apoptosis via reduced fatty acid synthesis in MDA-MB-231 cells
}

\author{
Jagatheesh Kaliaperumal $^{1}$ - Natarajan Hari $^{2} \cdot$ Padarthi Pavankumar $^{1} \cdot$ \\ Namasivayam Elangovan ${ }^{1}$
}

Received: 2 January 2015 / Accepted: 3 June 2015 / Published online: 29 June 2015

(C) The Author(s) 2015. This article is published with open access at Springerlink.com

\begin{abstract}
The development of formulations with therapeutic peptides has been restricted to poor cell penetration and in this attempt; we developed pACC1 peptide loaded chitosan nanoparticles. The prepared nanoparticles were characterized with FT-IR, XRD, SEM and TEM. In addition, the suitable formulation was evaluated for hemocompatibility, plasma stability and embryo toxicity using Danio rerio embryo model. The results showed that pACC1 peptide loaded chitosan nanoparticles were compatible with plasma. They possess sustained release pattern and also found to be safe up to $300 \mathrm{mg} / \mathrm{L}$ in embryo toxicity tests. Cytotoxicity assays with MDA-MB-231 cell lines suggested that, pACC1 peptide loaded chitosan nanoparticles were capable of enhanced cellular penetration and reduced palmitic acid content, which was confirmed by $\mathrm{H}^{1}$ NMR Hence, these nanoparticles could be employed as excellent adjuvant therapeutics while treating solid tumors with multi-drug resistance.
\end{abstract}

Keywords Peptide pACC1 - Chitosan - Nanoparticles . Danio rerio $\cdot$ Cytotoxicity $\cdot \mathrm{NMR} \mathrm{H}^{1}$

Namasivayam Elangovan

elangovannn@gmail.com

1 Molecular Pharmacology Research Laboratory, Department of Biotechnology, School of Biosciences, Periyar University, Salem, India

2 School of Chemical and Biotechnology, SASTRA University, Thanjavur, India

\section{Introduction}

Nowadays, most of the drugs developed with the aid of biotechnology intend to bind to a protein target, which may alter the protein's behavior. Protein interactions crucially mediate many biochemical pathways in controlling cellular proliferation and apoptosis. It has been endorsed that such interactions hold great therapeutic potential for the development of anti-cancer drugs. Peptides are highly suitable candidates for cancer targets because of advantages like small molecular size, simplicity associated with synthesis and modification process, tumor penetrating potential and biocompatibility. However, peptides also demonstrate some critical drawbacks, such as short plasma half life, poor oral bioavailability and different administration routes that could affect their pharmacokinetics and biological activities (Borghouts et al. 2005). Nanoparticles possess higher ability in delivery of proteins and nucleic acids principally into tumor cells, and moreover, they can preferentially accrue in the tumor tissues greater than what they do in normal tissues. This phenomenon is a significant advantage with regard to cancer targeted drug delivery (Grant and Leone-Bay 2012). Under pathological conditions, leakiness of tumor vasculature is a positive prospect for facilitating tissue penetration of nanoparticles. In addition, the nanoparticles facilitate the endosomal escape (Grant and Leone-Bay 2012; Matsumura and Maeda 1986; Erazo-Oliveras et al. 2012). Thus, the above mentioned drawbacks could be overcome by the peptides with the help of nano carriers. The selection of a biocompatible polymer is an imperative step in the delivery of peptides in an effective manner. Principally, they yield a constant release with a simple monolithic device; the slow matrix degradation can retain the levels of peptides in plasma, thereby increasing the permeability of peptides in tissues. Existing 
literature has confirmed that up-regulation of de novo lipogenesis in cancer cells is a crucial phenomenon that happens spontaneously to satisfy the energy demand (Shen and Tong 2008). Recently, the peptide pACC1 (sequence from acetyl-CoA carboxylase 1 1258-1271aa) has been identified and considered as a novel binding partner for the BRCT domain of the BRCA1 in a phosphorylation-dependant manner (Magnard et al. 2002; Ray et al. 2006; Brunet et al. 2008). This interaction might address its greater therapeutic value in suppressing cancer cell proliferation by blocking membrane synthesis and saturation through inhibiting fatty acid biosynthesis. In the present investigation, peptide pACC1 was checked for the compatibility with different polymers, chitosan based peptide pACC1 polymeric nanoformulation was developed and reported first time for their biocompatibility and cytotoxicity using MDA-MB-231 cells lines.

\section{Materials and methods}

\section{Materials}

Synthesized custom peptide pACC1 was procured from BioConcept Labs (Delhi, India). HPLC grade chemicals were purchased from Merck Millipore (India). Gelatin (type A), sodium alginate, chitosan (medium molecular weight) and sodium tripolyphosphate were purchased from Sigma Aldrich (Bangalore, India). Cell culture media (RPMI-1640) and fetal bovine serum (FBS) were purchased from GIBCO/BRL Invitrogen (Caithershurg, MD). Trypsin, methylthiazolyldiphenyl-tetrazolium bromide (MTT), and dimethyl sulfoxide (DMSO) were purchased from (SISCO research laboratory chemicals Mumbai). All other chemicals used were of analytical grade.

\section{Preparation of nanoparticles}

With an objective to evaluate the polymer peptide compatibility, the pilot study was carried out with three peptide compatibles.

\section{pACC1-Chitosan nanoparticles}

Chitosan nanoparticles were prepared by ionic crosslinking of chitosan with sodium tripolyphosphate (TPP) anions (Haliza Katas et al. 2012). Chitosan $(2 \mathrm{mg} / \mathrm{mL})$ was dissolved in acetic acid $(0.25 \% \mathrm{v} / \mathrm{v})$ with constant stirring at $10{ }^{\circ} \mathrm{C}$. Aqueous solution of TPP $(0.75 \% \mathrm{w} / \mathrm{v})$ was added (2:1 ratio) into chitosan solution containing $100 \mu \mathrm{g} / \mathrm{ml}$ of pACC1 peptide with continuous stirring for $6 \mathrm{~h}$. The resultant dispersion was centrifuged at $13,000 \times g$ for $20 \mathrm{~min}$ at $4{ }^{\circ} \mathrm{C}$. The supernatant was then removed and peptide chitosan nanoparticles $(\mathrm{PCN})$ were collected and freeze-dried $\left(-55^{\circ} \mathrm{C}\right)$.

\section{pACC1-gelatin nanoparticles}

Gelatin peptide nanoparticles (GPN) were prepared by twostep desolvation method with slight modifications (Azimi et al. 2014; Ofokansi et al. 2010). Briefly, gelatin (100 mg) was dissolved in distilled water $(5 \mathrm{~mL})$ under constant heating at $37{ }^{\circ} \mathrm{C}$ and adjusted to $\mathrm{pH} 4$. pACC1 peptide $(1 \mathrm{mg})$ was added into the gelatin solution followed by acetone $(12 \mathrm{~mL})$. Further, aqueous solution of glutaraldehyde $(25 \% \mathrm{v} / \mathrm{v})$ was added as a crosslinking agent and the solution was stirred continuously for $6 \mathrm{~h}$ at $4{ }^{\circ} \mathrm{C}$. The resultant was sonicated (sonitvibra cell, UC130, USA, amp-20, pulser-5 s) and centrifuged $(13,000 \times g)$ for $30 \mathrm{~min}$ at $4{ }^{\circ} \mathrm{C}$. The particles were washed with distilled water and freeze-dried.

\section{pACC1-sodium alginate nanoparticles}

Sodium alginate peptide nanoparticles (SPN) were prepared by controlled ionic gelation method (Catarina et al. 2006; Saeed et al. 2013). Briefly, $2 \mathrm{~mL}$ of calcium chloride $(18 \mathrm{mM})$ was added to $38 \mathrm{~mL}$ of sodium alginate solution $(0.1 \% \mathrm{w} / \mathrm{v})$ to promote gelation. Ten milliliters of peptide pACC1 $(0.1 \% \mathrm{w} / \mathrm{v})$ was added to calcium alginate solution to form nanoparticles. The suspension was stirred for $2 \mathrm{~h}$ and kept overnight for stabilization. The nanoparticles were subjected to centrifugation $(13,000 \times g)$ for $45 \mathrm{~min}$ at $4{ }^{\circ} \mathrm{C}$.

\section{Peptide polymer compatibility study}

The interaction between $\mathrm{pACC} 1$ peptide and polymer was conferred with FT-IR (Perkin Elmer, Spectrum-RX1, USA) spectra in range of $400-4000 \mathrm{~cm}^{-1}$. X-ray diffraction studies were performed for chitosan and PCN to confirm the non existence of crystalline structure.

\section{Characterization of PCN}

The Chitosan nanoparticles were formulated by keeping constant peptide pACC1 concentration and different ratios of chitosan. Different concentrations of chitosan [0.1, 0.2, $0.3,0.4$, and $0.5 \%(\mathrm{w} / \mathrm{v})]$ were obtained by dissolving in acetic acid $(0.25 \% \mathrm{v} / \mathrm{v})$ under constant stirring $(250 \mathrm{rpm})$ overnight. Twenty milliliter of TPP $0.75 \%(\mathrm{w} / \mathrm{v})$ was added into $10 \mathrm{~mL}$ chitosan solution containing $0.20 \mathrm{mg}$ of pACC1 peptide and stirring was raised to $320 \mathrm{rpm}$ for $6 \mathrm{~h}$ at $4{ }^{\circ} \mathrm{C}$. The resultant dispersion was subjected to sonication (Sonitvibra cell, UC130, USA, Amplitude-20, Pulser$4 \mathrm{~s}$ ) for $10 \mathrm{~min}$ at $4{ }^{\circ} \mathrm{C}$. Further, the dispersion was washed thrice $(2200 \times g)$ and re-dispersed in HPLC grade water 
(LiChrosolv) and again centrifuged at $13,000 \times g$ for 20 min at $4{ }^{\circ} \mathrm{C}$ to obtain five different peptide polymer ratio formulations (PCN-J01 to PCN-J05). Finally, the nanoparticles were freeze-dried (Delvac-lyo1550, INDIA) and stored at $-20{ }^{\circ} \mathrm{C}$ for further characterization.

\section{Process yield}

The freeze-dried formulations (PCN-J01 to PCN-J05) were weighed to calculate the process yield as previously described (Nesalin and Smith 2012). The results were expressed as mean values obtained from three replicates.

\section{Association and loading efficiency}

Association efficiency (AE) and loading efficiency (LE) were calculated based on previous methods with slight modification (Ma et al. 2002). PCN were pelletized at $5800 \times g$ and supernatant was quantified for peptide by RPHPLC method developed in our laboratory (Jagatheesh et al. 2014). The formulae mentioned below were used to calculate AE and LE.

$$
\begin{aligned}
\mathrm{AE}= & \frac{\text { Total amount of Peptide }- \text { Peptide in supernatant }}{\text { Total amount of Peptide }} \\
& \times 100 \quad
\end{aligned}
$$$$
\begin{aligned}
\mathrm{LE}= & \frac{\text { Total amount of Peptide }- \text { Peptide in supernatant }}{\text { Weight } \text { of recovered nanoparticles }} \\
& \times 100
\end{aligned}
$$

\section{In vitro peptide release}

In vitro release of formulations (PCN-J01 to PCN-J05) was determined by plasma simulation (Narayanan et al. 2013) and dialysis membrane method (Hu et al. 2002) with slight modifications. Briefly, the formulations was redispersed in $10 \mathrm{~mL}$ of $\mathrm{NaCl}(0.9 \%$ w/v) with final peptide concentration of $20 \mu \mathrm{g} / \mathrm{mL}$. One milliliter of the above mentioned mixture was added to $10 \mathrm{~mL}$ of PBS (0.5 M, pH 7.4) and $10 \mathrm{~mL}$ of suspended blood cells were added. The suspension was kept in orbital shaker at $37^{\circ} \mathrm{C}$. One milliliter of released solution was collected at different time intervals and replaced with fresh solution. The harvested solutions were centrifuged and supernatant was used to analyze peptide content by RP-HPLC (Jagatheesh et al. 2014). The release rate was calculated using following equation

Peptide release $\%$

$$
=\frac{\text { Amount of Peptide released at time " } \mathrm{t} \text { " }}{\text { Amount of Peptide loaded in the naoformulation }} \times 100
$$

In dialysis membrane method, $2 \mathrm{mg}$ of formulations (PCN-J01 to PCN-J05) was redispersed in $10 \mathrm{~mL}$ of PBS
$(0.5 \mathrm{M} \mathrm{pH} 7.4)$, placed in dialysis membrane (cut-off $10 \mathrm{kDa})$ and dialyzed against PBS (0.5 M pH 7.4). Two milliliter of released solution was collected at different time intervals, replaced with fresh solution and analyzed by RP-HPLC by calibration curve method.

\section{Particle size distribution and zeta potentials}

The size distribution and zeta potentials of formulations (PCN-J01 to PCN-J05) were measured by Zeta Sizer (Malvern, Mastersizer 2000, UK). Sample was dispersed in water ( $\mathrm{pH} 7.4)$ and the particles were counted in $4.8 \mathrm{~mm}$ calibrated area with the count rate of $210.3 \mathrm{Kcps}$ for $70 \mathrm{~s}$. The analysis was performed in triplicates and mean values were reported.

\section{Kinetic modeling}

To determine the suitable drug release kinetic model describing the mechanism dissolution profile, the result of in vitro release obtained from two methods were fitted with various kinetic equations such as zero order, first order, Higuchi's model and Peppas plot methods (Dash et al. 2010).

\section{Surface morphology}

Scanning electron microscopy (TESCAN, VEGA3 SBU, Czech) of the chitosan nanoparticles were performed to observe the particle size and surface morphology. The size and shape of the nanoparticles were further characterized using the transmission electron microscope (Jeol, JEM2100, Japan).

\section{Hemocompatibility}

Hemocompatibility was evaluated as previously reported (Pooja et al. 2014), using Triton X-100 (1\%) and normal saline as negative and positive control, respectively.

\section{Embryo toxicity}

The Danio rerio was maintained as female/male (2:1 ratio) in $23 \times 30 \times 23 \mathrm{~cm}$ glass aquarium at an average temperature of $26 \pm 1{ }^{\circ} \mathrm{C}$ and $14 \mathrm{~h} / 10 \mathrm{~h}$ light dark cycle (Zhu et al. 2008). The spawning was goaded in the morning $6-7(+5.30$ GMT). After $30 \mathrm{~min}$, the embryos were collected and maintained in E3 medium. Healthy embryos $(n=96)$ were collected and exposed to PCN-J04, 4-5 h post fertilization. Each well contained 12 embryos with different concentrations of PCN-J04 (1, 3, 10, 30, 100, 300, $1000 \mathrm{mg} / \mathrm{L})$. Throughout the experiment, the developmental status of the

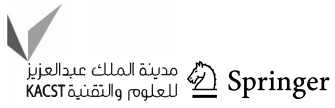



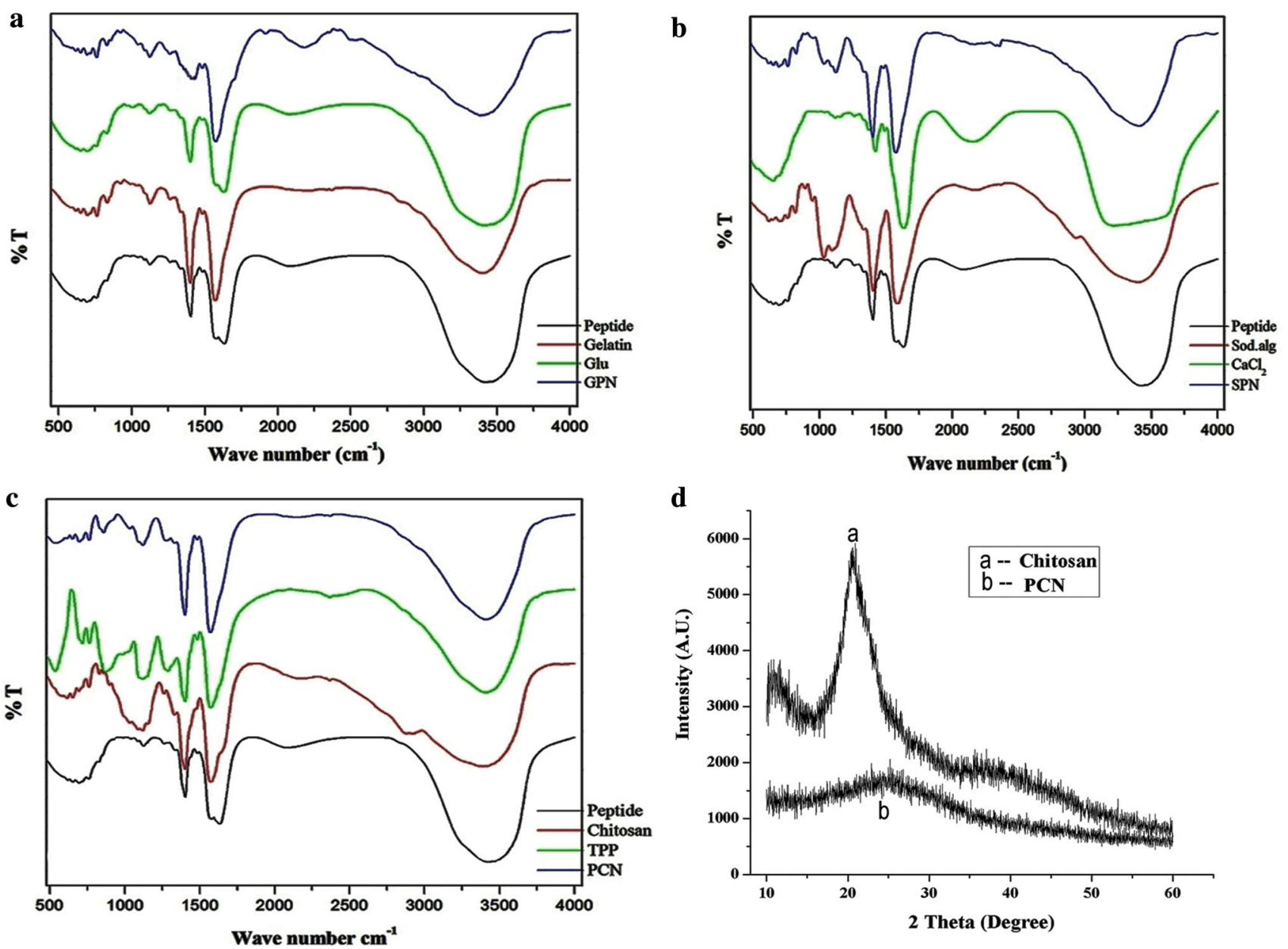

Fig. 1 FT-IR spectra for polymer peptide compatibility: a Gelatinpeptide pACC 1 compatibility. Black manifestation shows the peptide pACC1, red manifestation denotes FT-IR spectrum of gelatin, green manifestation shows FT-IR spectrum of glutaraldehyde (Cross linker)

Danio rerio embryos and larvae was observed under compound microscope (Olympus, MLXi, Japan) at different time intervals. The toxicity was assessed with multiple parameters such as embryo/larva survival, hatching rate and malformations including tissue ulceration, pericardial edema and body arcuation.

\section{Plasma stability}

Fresh blood (Wister rat) was collected in heparinized tubes and plasma was separated by centrifugation $(1800 \times g$ for 15 min at $4{ }^{\circ} \mathrm{C}$ ). Separated plasma was incubated at $37{ }^{\circ} \mathrm{C}$ for $30 \mathrm{~min}$ in $0.9 \% \mathrm{w} / \mathrm{v}$ of $\mathrm{NaCl}$ solution and PCN-J04 $(10 \mu \mathrm{g})$ was added. At regular intervals, plasma solution ( $1 \mathrm{~mL}$ ) was collected and stored at $-20{ }^{\circ} \mathrm{C}$ until use. After centrifugation $(17,000 \times g 20 \mathrm{~min})$, peptide content was analyzed by HPLC (Jagatheesh et al. 2014).

and blue manifestation shows FT-IR spectrum of GPN; b FT-IR spectra for sodium alginate-peptide pACC1 compatibility; c FT-IR spectra for chitosan-peptide pACC1 compatibility and d XRD Spectrum of chitosan and chitosan peptide pACC1 nanoparticles

\section{In vitro Cytotoxicity}

Human breast cancer MDA-MB-231 (GDC055) cell lines were obtained from National Center for Cell Science, Pune (NCCS). The cells were maintained in RPMI-1640 supplemented with $10 \%$ FBS, penicillin $(100 \mathrm{U} / \mathrm{mL})$, and streptomycin $(100 \mu \mathrm{g} / \mathrm{mL})$ in a humidified atmosphere of $5 \% \mathrm{CO}_{2}$ at $37{ }^{\circ} \mathrm{C}$.

The cytotoxicity of PCN-J04 on MDA-MB-231 cells was determined by the MTT assay (Lagopati et al. 2014). Cells $\left(1 \times 10^{5} /\right.$ well $)$ were plated in $100 \mu \mathrm{l}$ of medium/well in 96-well plates. $80 \%$ confluence of cells was incubated in the presence of various concentrations of the PCN-J04 in DMSO $(0.1 \%)$ for $48 \mathrm{~h}$ at $37{ }^{\circ} \mathrm{C}$. After removal of the medium, cells were washed with PBS (pH 7.4) and incubated with MTT for $4 \mathrm{~h}$. Viable cells were determined by the absorbance measured at $570 \mathrm{~nm}$ with microplate reader 


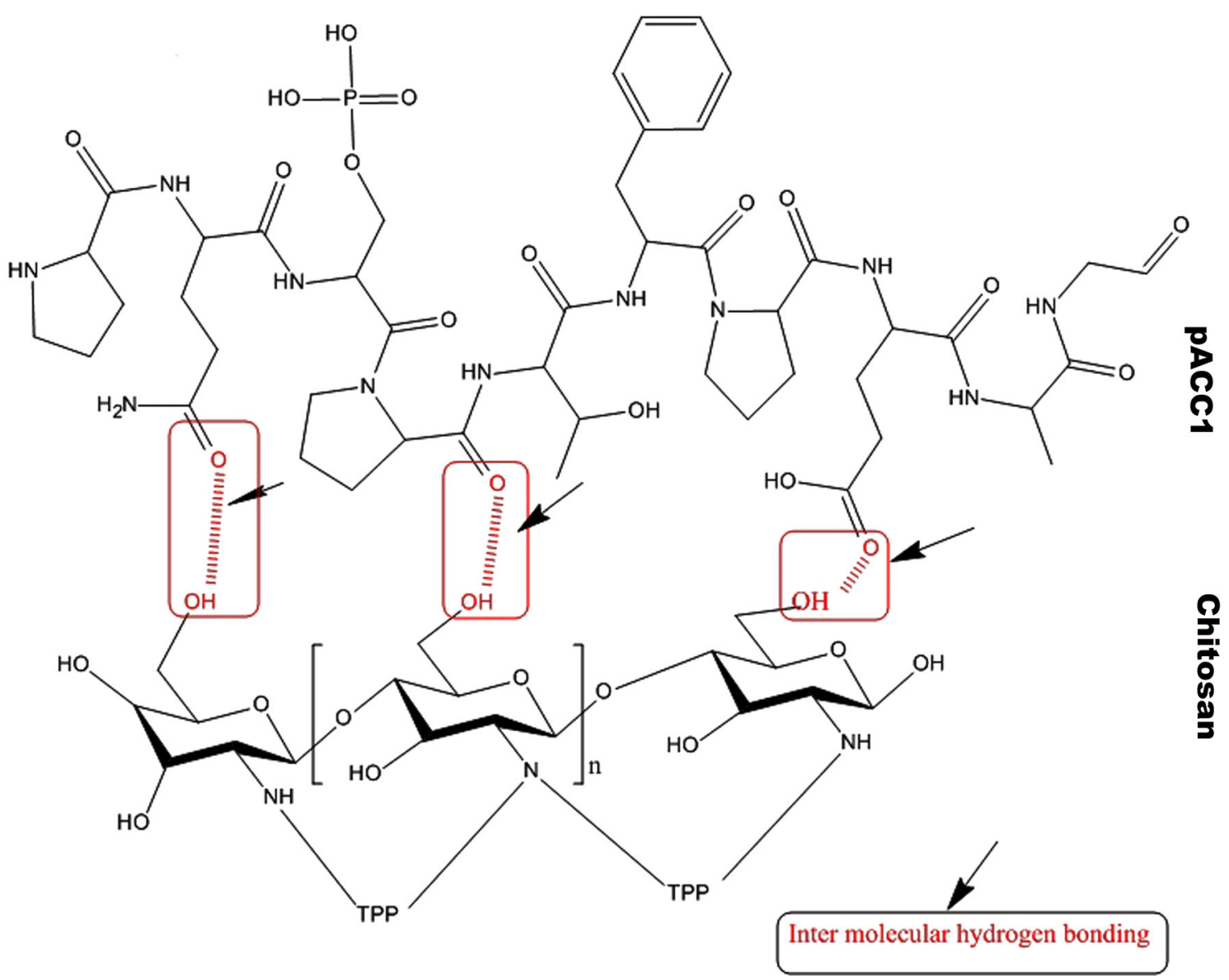

Fig. 2 Representation of intermolecular hydrogen bonding between peptide pACC1 $(=\mathrm{O})$ and chitosan $(\mathrm{HO})$

Table 1 Pharmaceutical characteristics of formulations (J01-J05)

\begin{tabular}{lllllll}
\hline $\begin{array}{l}\text { Batch } \\
\text { code }\end{array}$ & $\begin{array}{l}\text { Peptide chitosan } \\
\text { ratio }\end{array}$ & $\begin{array}{l}\text { Process yield } \\
(\%)\end{array}$ & AE $(\%)$ & LE $(\%)$ & $\begin{array}{l}\text { Z average } \\
(\text { day nm })\end{array}$ & $\begin{array}{c}\text { PDI }(Ð) \\
\text { Zeta potential } \\
(\mathrm{mV})\end{array}$ \\
\hline $\mathrm{J} 01$ & $1: 0.5$ & $50.60 \pm 1.44$ & $41.150 \pm 1.65$ & $35.474 \pm 2.43$ & $322.9 \pm 22$ & $0.287 \pm 0.023+37 \pm 2.9$ \\
$\mathrm{~J} 02$ & $1: 1$ & $80.25 \pm 4.00$ & $47.715 \pm 2.69$ & $50.760 \pm 3.22$ & $368.1 \pm 25$ & $0.345 \pm 0.032+31 \pm 2.7$ \\
$\mathrm{~J} 03$ & $1: 1.5$ & $79.63 \pm 3.34$ & $61.110 \pm 2.76$ & $53.371 \pm 2.34$ & $397.6 \pm 21$ & $0.245 \pm 0.042+35 \pm 3.4$ \\
$\mathrm{~J} 04$ & $1: 2$ & $83.57 \pm 3.56$ & $61.170 \pm 2.97$ & $58.535 \pm 3.98$ & $402.7 \pm 33$ & $0.199 \pm 0.012+39 \pm 2.4$ \\
$\mathrm{~J} 05$ & $1: 2.5$ & $87.23 \pm 4.60$ & $66.161 \pm 2.39$ & $62.712 \pm 1.99$ & $532.3 \pm 27$ & $0.406 \pm 0.033+36 \pm 3.2$ \\
\hline
\end{tabular}

All values were expressed mean of three replicates with $\pm \mathrm{SE}$

(Bio-Rad, USA). The effect of the samples on the proliferation of human breast cancer cells was expressed as the $\%$ cell viability, using the following formula:

$\%$ cell viability $=$ A570 of treated cells $/$ A570 of control cells $\times 100 \%$

The optimum dose of PCN-J04 was fixed based on $50 \%$ inhibitory concentration.

\section{Apoptosis analysis using duel staining}

The cells were plated at a density of $5 \times 10^{4}$ in 6-well plates and were allowed to grow till $80 \%$ confluence. Then, cells were treated with different concentrations of PCN-J04 for $24 \mathrm{~h}$. The culture medium was aspirated from each well and cells were gently rinsed twice with PBS and subsequently treated with $100 \mu \mathrm{l}$ of ethidium bromide and acridine orange (1:1 w/w) (Kasibhatla et al. 2006). Viewed 
immediately under Fluorescence Microscope (Olympus, MLXi, Japan). The percentage of apoptotic cells was determined as follows:

$\%$ of apoptotic cells

$=($ total number of apoptotic cells

/total number of cells counted) $\times 100$

\section{Estimation of lipids by $\mathrm{H}^{\mathbf{1}}$ NMR}

Eighty percentage confluence of cells were incubated in presence of $7.66 \mu \mathrm{g} / \mathrm{mL}$ of final concentration of peptide containing PCN-J04 for $48 \mathrm{~h}$, and the cellular lipids were isolated by previously described method (Folch et al. 1957). The freeze-dried samples of control and PCN-J04 treated cellular lipids were used for one dimensional $\mathrm{H}^{1}$ NMR spectrum by dissolving in $600 \mu \mathrm{L}$ of Acetone- $\mathrm{d}_{6}$ (Merck KGaA, Germany) and spectrum acquired with $300 \mathrm{MHz}$ AVANCE II (Bruker BioSpin, Switzerland) spectrometer equipped with a $5 \mathrm{~mm}$ BBO probe (Bruker BioSpin, Switzerland). The experiments were recorded at 297.15 K using the standard pulse sequence library of TopSpin 1.3 (Bruker BioSpin, Switzerland) followed by processing of the data by using TopSpin 1.3 (Bruker BioSpin, Switzerland) software. The $\mathrm{H}^{1} \mathrm{NMR}$ spectra of control and PCN-JO4 were overlaid and the difference spectra were arrived using the tool available in TopSpin and the comparison was made with the identical scaling factor.

\section{Statistical analysis}

All the above experiments were performed thrice independently, with triplicates. The statistical analysis was performed using Graphpad prism (version 5.0). Results were expressed as mean $\pm \mathrm{SE}$. The standard error values are indicated as error bars in the corresponding graphs. Two way analysis of variance (ANOVA) with Bonferroni post-tests comparisons was used to detect the significance between the groups. ${ }^{*} p<0.05$ was considered to be statistically significant.

\section{Results and discussion}

\section{Selection of polymer}

The FT-IR spectrum (Fig. 1a-c) shows multiple polymers and their interactions with peptide. The spectra of peptide (Fig. 1a) show significant peaks at $3432 \mathrm{~cm}^{-1}(\mathrm{O}-\mathrm{H}$ stretching), $1633 \mathrm{~cm}^{-1}$ (C=N stretching), $1579 \mathrm{~cm}^{-1}(\mathrm{~N}-\mathrm{H}$ stretching) and $1402 \mathrm{~cm}^{-1}(\mathrm{C}=\mathrm{O}$ stretching). In chitosan spectra (Fig. 1c), the peaks were observed at $3392 \mathrm{~cm}^{-1}$ (N-H stretching), $1574 \mathrm{~cm}^{-1} \quad(\mathrm{~N}=\mathrm{N} \quad$ stretching $)$ and $1462 \mathrm{~cm}^{-1}$ (C=C stretching). The PCN spectra show sharp peak at $3408 \mathrm{~cm}^{-1}(\mathrm{O}-\mathrm{H})$ and $1402 \mathrm{~cm}^{-1}(\mathrm{C}=\mathrm{O})$ (Fig. 1c). The broadening of peak at $3408 \mathrm{~cm}^{-1}$ was due to the intermolecular hydrogen bonding between chitosan and peptide. According to Flory-Huggins theory (Flory 1953), the intermolecular hydrogen bonding in PCN (Fig. 2) has been attributed to the strong interaction between hetero atoms and the carbonyl of amide $(\mathrm{C}=\mathrm{O}-\mathrm{HO})$. The absence of peak at $1400-1600 \mathrm{~cm}^{-1}(\mathrm{C}=\mathrm{O}$ stretching) in GPN might be due to ionic bonding between polymer and peptide. The spectrum of sodium alginate was observed in the peak range of $1400-1600 \mathrm{~cm}^{-1}$ but the peak broadening (Fig. 1b) was not appreciable as compared to PCN. Hence, it might be suspected as very weak interaction (van der
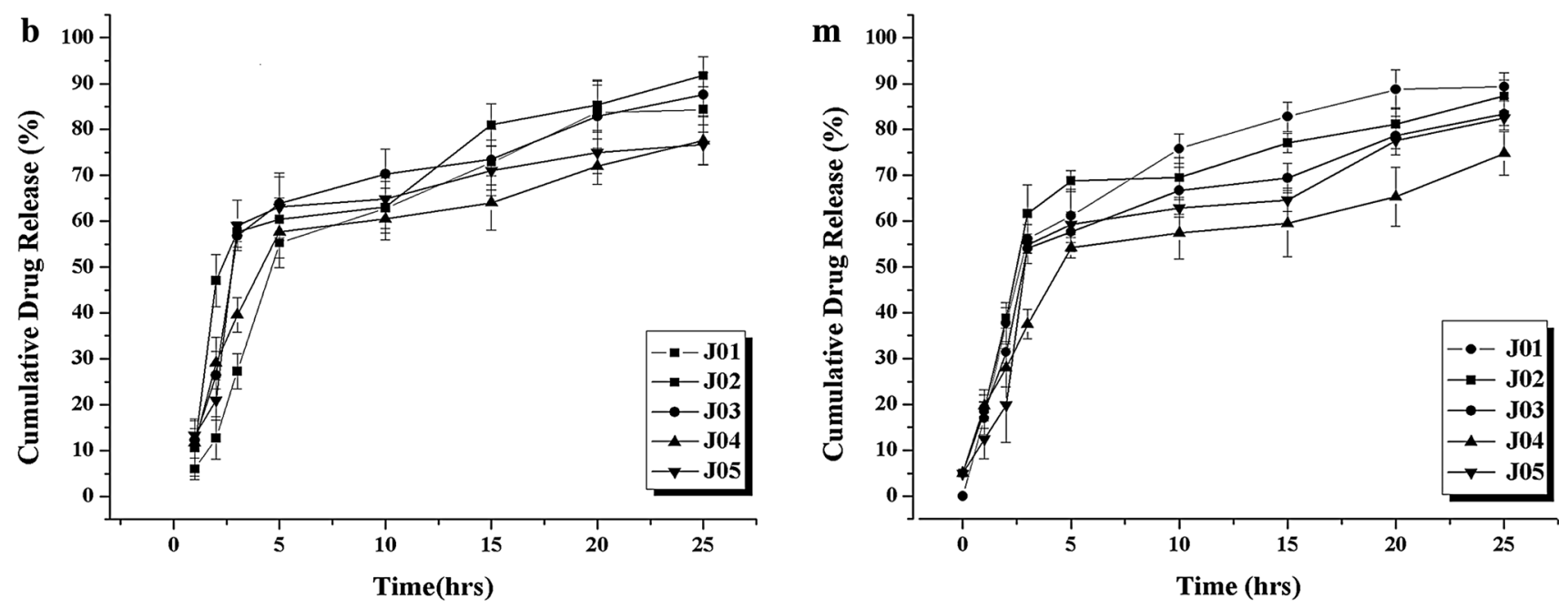

Fig. 3 In vitro release profiles of pACC1 peptide from different formulations estimated by plasma simulation method; b release profile of peptide pACC1 from formulations predicted by dialysis membrane method $\mathbf{m}$ values are expressed \pm SE of three replicates 
Table 2 Release kinetics and mechanism of drug release

\begin{tabular}{|c|c|c|c|c|c|c|c|}
\hline Batch code & Cumulative drug release $(\%)$ & Zero order & First order & Higuchi plot & Peppas plot & $n$ value & Hixsson \\
\hline \multicolumn{8}{|c|}{ Simulated blood plasma method } \\
\hline J01 & 84.35 & 0.837 & 0.569 & 0.936 & 0.792 & 1.081 & 0.040 \\
\hline $\mathrm{J} 02$ & 82.20 & 0.737 & 0.410 & 0.883 & 0.646 & 0.977 & 0.059 \\
\hline $\mathrm{J} 03$ & 78.37 & 0.734 & 0.449 & 0.882 & 0.687 & 0.977 & 0.067 \\
\hline J04 & 68.83 & 0.757 & 0.450 & 0.902 & 0.702 & 0.965 & 0.087 \\
\hline $\mathrm{J} 05$ & 62.15 & 0.538 & 0.407 & 0.726 & 0.640 & 0.910 & 0.099 \\
\hline \multicolumn{8}{|c|}{ Dialysis membrane method } \\
\hline J01 & 89.35 & 0.726 & 0.376 & 0.907 & 0.562 & 0.869 & 0.028 \\
\hline J02 & 82.30 & 0.660 & 0.356 & 0.847 & 0.559 & 0.854 & 0.069 \\
\hline $\mathrm{J} 03$ & 78.35 & 0.741 & 0.390 & 0.904 & 0.593 & 0.861 & 0.070 \\
\hline $\mathrm{J} 04$ & 68.85 & 0.767 & 0.391 & 0.924 & 0.589 & 0.816 & 0.089 \\
\hline J05 & 66.00 & 0.612 & 0.428 & 0.788 & 0.660 & 0.930 & 0.092 \\
\hline
\end{tabular}
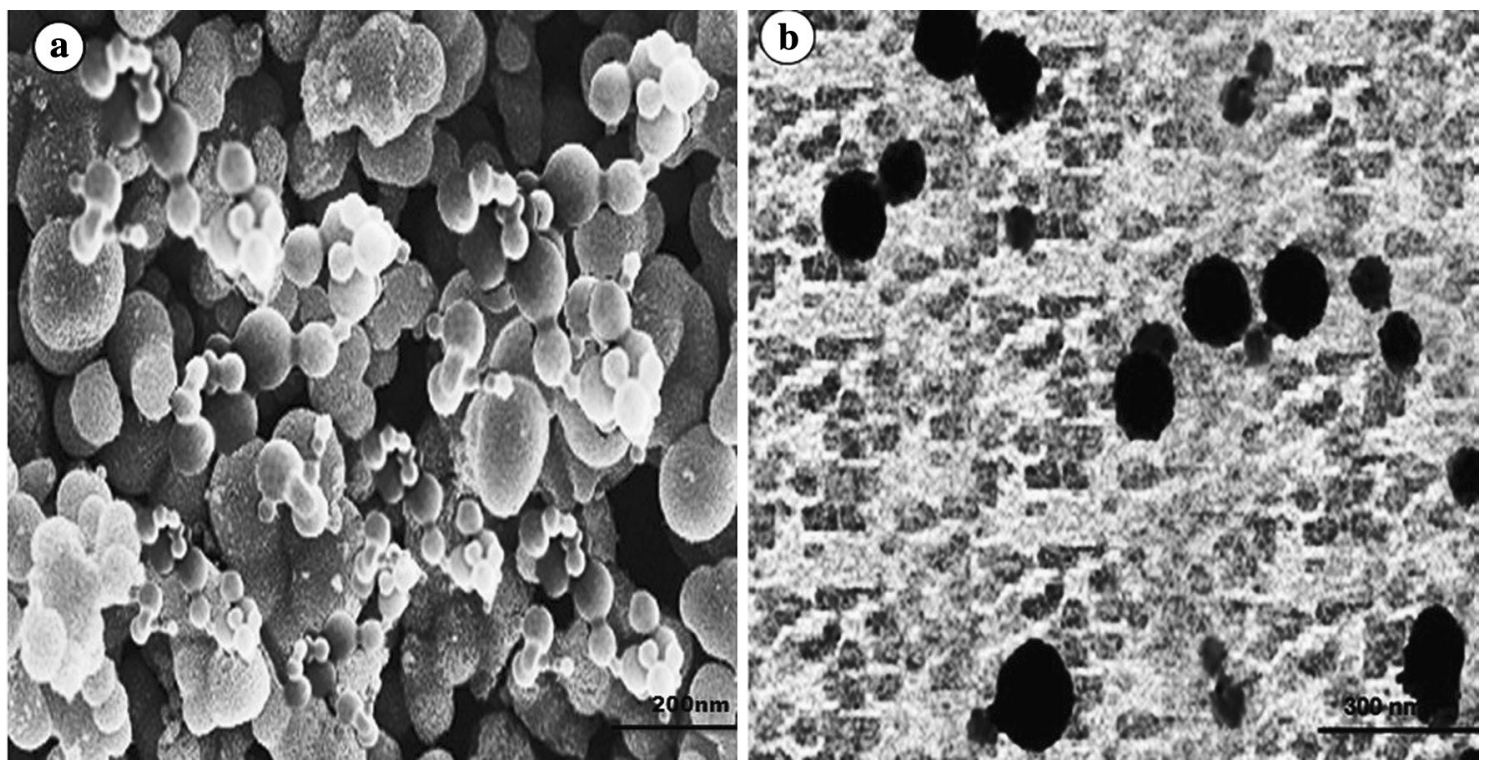

Fig. 4 Surface morphology of PCN-J04. a SEM image shows typical nanoparticle distribution of PCN-J04; b TEM image of PCN-J04 showing particle size of 200-300 $\mathrm{nm}$

Waals interactions) between the groups, possibly due to lack of electro negativity.

Collectively, chitosan was found to be extremely compatible polymer with an ability of formation of intermolecular hydrogen bond. Hence, further studies were carried out with PCN.

\section{Optimization of peptide polymer ratio}

The present investigation was to find the effective peptide polymer ratio, by keeping constant peptide concentrations and variable chitosan concentrations. To find the ratio, the amount of peptide per unit of polymer was greater which might result in higher yield and efficiency. The result of process yield of formulations (PCN-J01 to PCN-J05) was found to be directly proportional to polymer ratio. The ratio of peptide and polymer $(1: 2.5 \mathrm{w} / \mathrm{w})$ showed higher degree of process yield when compared with other peptide polymer ratio, due to greater carbon efficiency (Table 1). Interestingly, the association and loading efficiencies of formulations increased with an increase in peptide polymer ratio (1:2.5). The greater association and loading efficiencies were due to reduced $\mathrm{pH}$ (6.5) experimental condition. Hence, the positively charged chitosan $(\mathrm{pKa} \sim 6.5)$ might depict greater attraction with negatively charged $\operatorname{pACC} 1(-2)$.

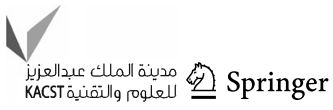




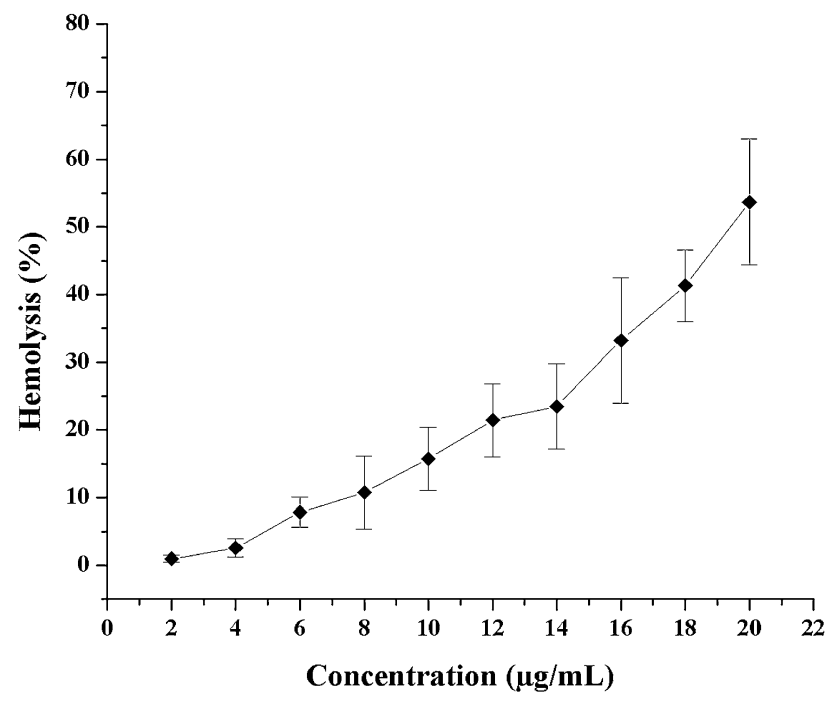

Fig. 5 Percentage hemolysis leads on treatment of different concentration of PCN-J04. Values are expressed $\pm \mathrm{SE}$ of three replicates

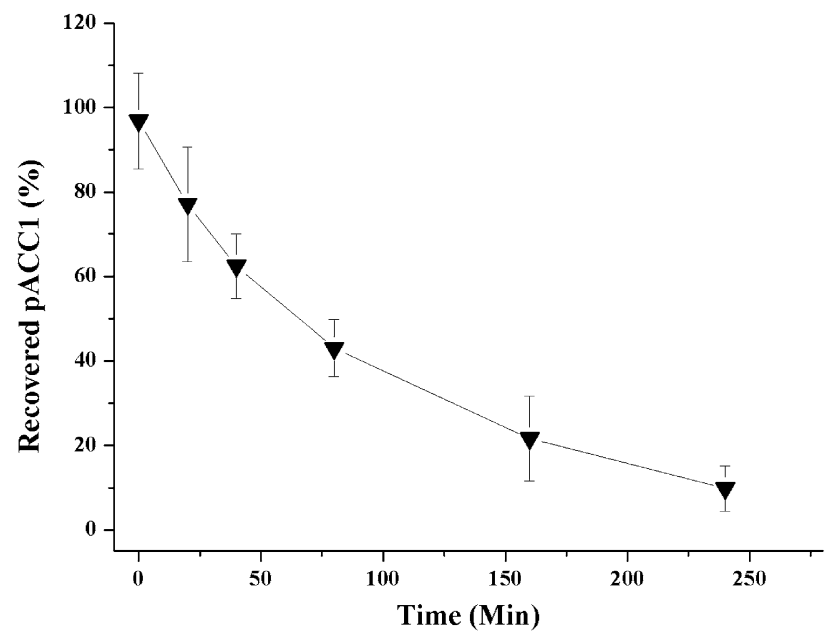

Fig. 6 Plasma liberation of peptide pACC1 at different time intervals form PCN-J04. Values are expressed \pm SE of three replicates

The mean particle size of formulations (PCN-J01 to PCN-J05) obtained by zeta seizer ranged from 322 to $532 \mathrm{~nm}$; this greater particle size when compared to TEM analysis (200-250 nm) might be due to swelling and formation of good polymeric networks of chitosan in the polar medium (water). The Polydispersity index (PDI) of formulations (PCN-J01 to PCN-J05) was maintained on an average between 0.287 and 0.406 . Formulation J04 possessed less PDI of 0.199 when compared with all other peptide polymer ratios. The DLVO theory states that stability of particle in the dispersion depends on the balance between attractive and repulsive forces among the particles (Lin et al. 2014). Hence, the particles with PDI $<0.5$ are considerably stable, lesser agglomeration and travel faster in the circulatory system. As a result,
PCN-J04 displayed the capability to produce faster onset of action and was comparatively stable with other formulation batches. Further, all the formulations batches were positively charged between +36 and $+39 \mathrm{mV}$. Evidently, the cancer cell surfaces are usually negatively charged due to translocation of negatively charged constituents in the inner layer cell membrane such as phosphatidylserine, anionic phospholipids, glycoproteins and proteoglycans. Owing to the negative charges in the inner layer of cell membrane, tumor vasculature might have potentiated the electrostatic interaction between positively charged nanoparticles and negatively charged tumor cells. This might be responsible for the tumor-specific accumulation. In addition, the positively charged nanoparticles were retained for a longer time span in the tumor site when compared to negative or neutral particles. Since phosphatidyl serine is a negatively charge residue, it gets translocated to the surface of cancer cells.

\section{In vitro release determination}

The results of formulations (PCN-J01 to PCN-J05) release pattern showed (Fig. 3b, m) not much of variations in plasma simulation and membrane dialysis methods. The increased size of PCN decreased the rate of peptide release in $25 \mathrm{~h}$ pattern. The $50 \%$ release of peptide content was achieved between 3 and $10 \mathrm{~h}$ in most of the formulations. The results of the present study showed that increased AE was inversely proportional to the peptide release. Further, the study results showed that there is no 'burst' effect in both plasma simulation and membrane dialysis methods of in vitro release which assured that the formulations were not weakly bound. All formulations followed Higuchi diffusion with regression values ranging between $(0.788$ and 0.96). Hence, it can be hypothesized that preponderance release of peptide is accommodated by diffusion. Principally, Higuchi diffusion-driven release into the matrix was unaltered and it could be assumed that rate of solubility of chitosan exerted an influence in the release of peptide. Further, the swelling of the polymer favored single pore formation, through which sustained release would be achieved. On the whole, the formulation PCN-J04 encompassed fair $\mathrm{AE}$, zeta potential and good release linearity. Hence, further studies were carried out with PCNJO4 (Table 2).

\section{Characterization of PCN-J04}

The XRD spectrum (Fig. 1d) of chitosan showed a sharp peak in $23 \theta$ and the PCN did not have any sharp peaks over XRD. Sequentially, the peak got broader and there was a radical fall in height. This might be attributed to the fact that particles undergo microstress, obtain grain boundaries 

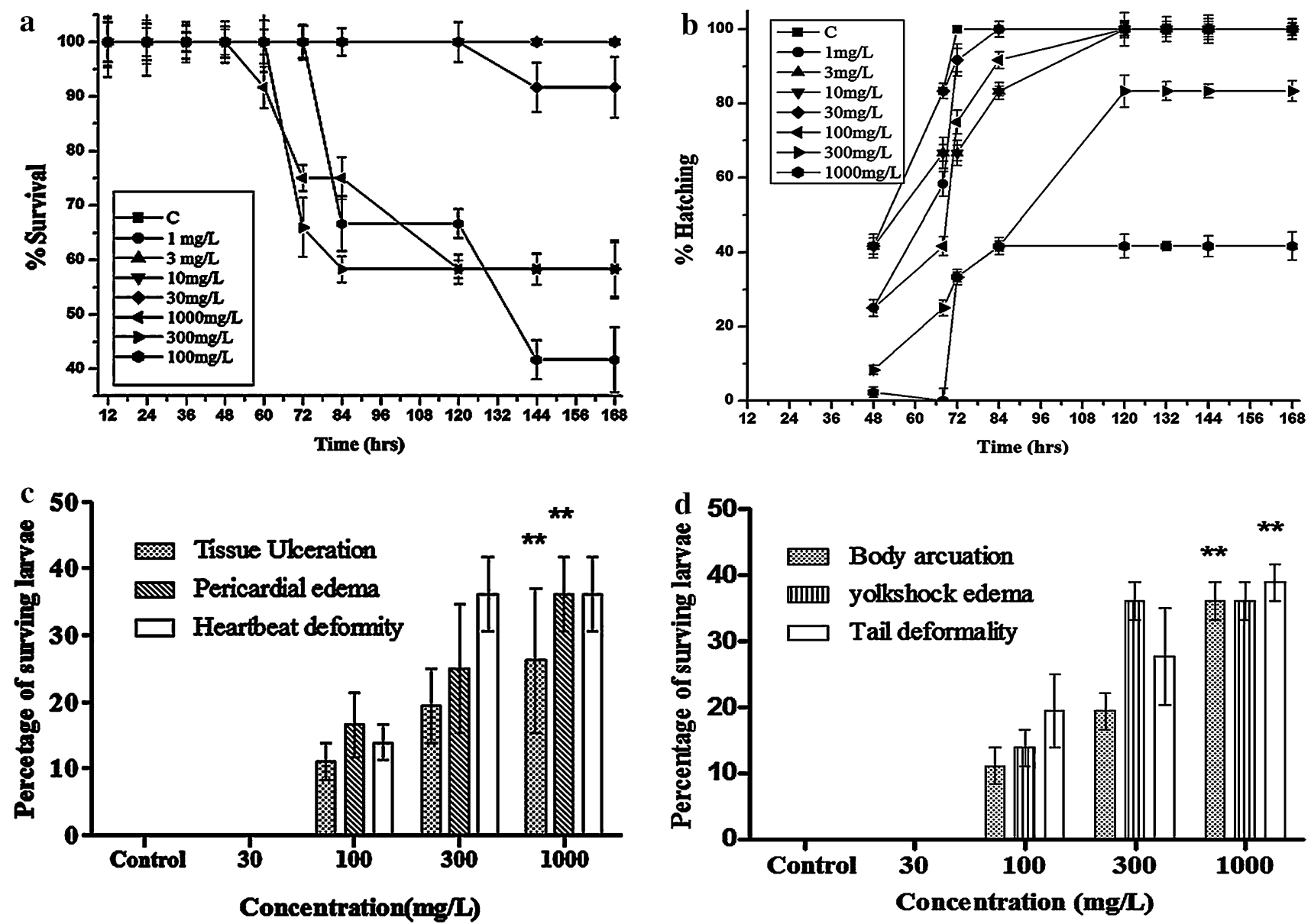

Fig. 7 Embryo toxicity of PCN-J04. a Effect of PCN-J04 on Danio rerio embryo survival rate; $\mathbf{b}$ hatching rate; $\mathbf{c}$, d percentage of surviving larvae with different deformities; values are expressed \pm SE of three replicates, ${ }^{* *} p<0.05$ vs pairs of columns

and sub-boundaries. According to law of Scherrer (Singh 2005), the shortening and peak broadening are evidences that the particles had gained nano-scale status. The ultra structural images of PCN-J04 (Fig. 4a, b) shows spherical shape particles, although appeared to be a little aggregated. This indicates that the incorporation of peptide as a solid structure contributed to the enhancement of morphology of nanoparticles. Further, there was no shearing on the surface of PCN-J04 due to the formation of intermolecular hydrogen bonding in multiple regions.

\section{Hemocompatibility of PCN-J04}

The results showed that the damage of the erythrocytes by PCN-J04 was insignificant even at higher concentrations $(14 \mu \mathrm{g} / \mathrm{mL})$ which might not be the case in normal therapy. Further, the increase in concentration of PCN-J04 increased the hemolytic property (Fig. 5). The reason might be chitosan interacts with the negatively charged membrane of erythrocytes by electrostatic attraction and triggers thrombus formation (Fig. 6).

\section{Plasma stability of PCN-J04}

The results of plasma stability studies for PCN-J04 were represented in Fig. 7. Results showed that PCN-J04 remain stable more than 60 min from chemical (acids) and enzymatic degradation which is suitable for nanoparticles to target tumor tissue. It is believed that movements of nanoparticles are fast when compared to macro molecules. Hence, it would reach the tissue compartment from central compartment within $60 \mathrm{~min}$. Further, the vascular leakage might also facilitate the nanoparticles entry into the tumor micro environment.

\section{Embryo toxicity assessment}

In the present investigation, the survival rate of larvae decreased with increasing concentration of PCN-J04 in the medium. The survival rate declined from $300 \mathrm{mg} / \mathrm{L}$, but more than $50 \%$ reduction was observed in $1000 \mathrm{mg} / \mathrm{L}$. The death rate of larvae was observed between 48 and $72 \mathrm{~h}$ when compared to control (Fig. 7a). The hatching rate of 

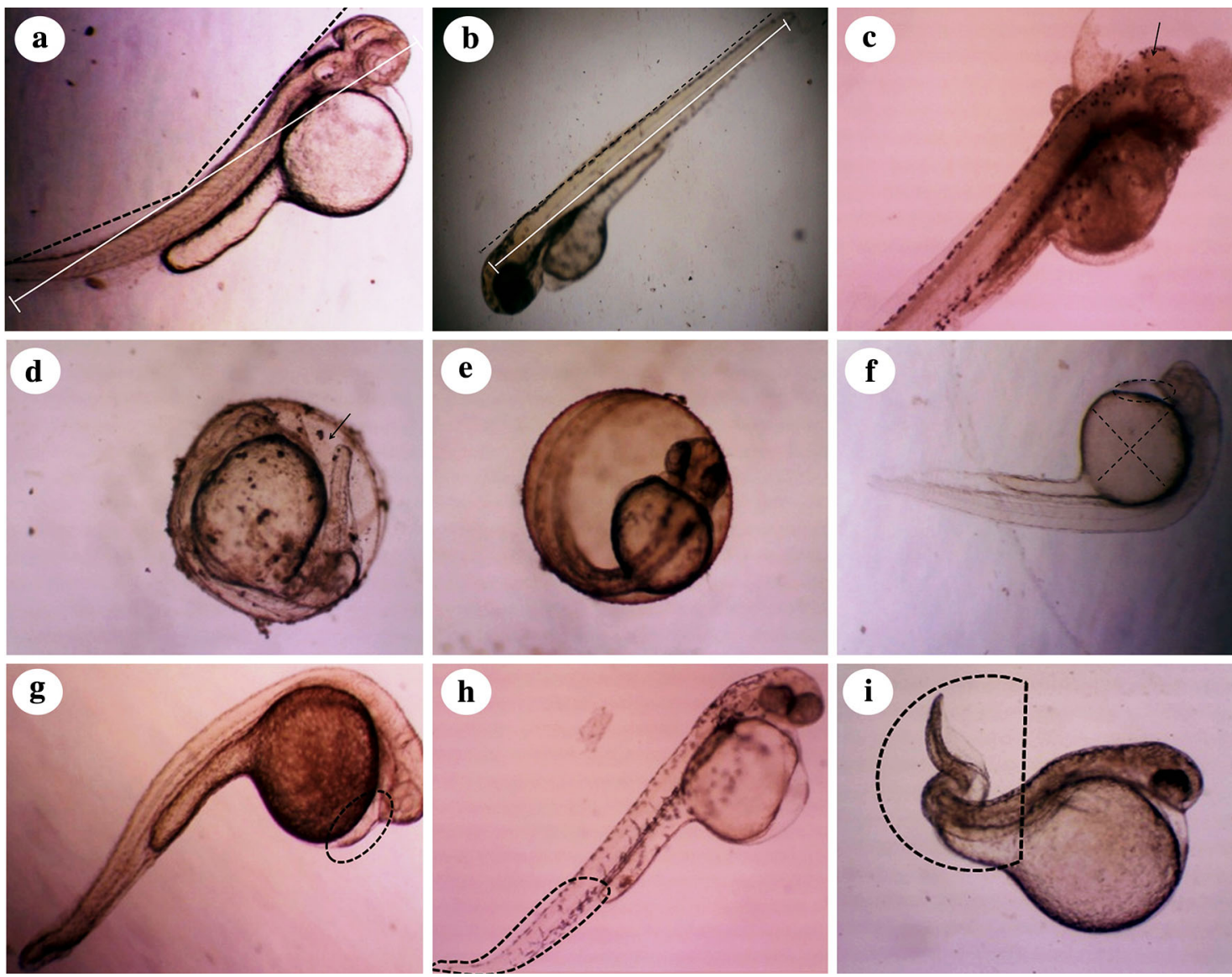

Fig. 8 Deformities of embryo-larvae. a Larvae with body arcuation deformity; $\mathbf{b}$ control larvae without any deformity; c, $\mathbf{d}$ larvae with tissue ulceration; e unhatching matured larvae; f, $\mathbf{g}$ pericardial and yolk sac edema; $\mathbf{h}, \mathbf{i}$ tail deformity larvae

larvae from chorionic membrane in all the concentrations of PCN-J04 and control occurred between 36 and $50 \mathrm{~h}$. The 300 and $1000 \mathrm{mg} / \mathrm{L}$ treated group showed significant delay in the percentage of hatching rate but the maximum hatching rate was observed in 60-72 h (Fig. 7b).

There is no tangible statement suggesting that Danio rerio genome has $B R C A 1$ orthologue. But it does have an orthologue of the BRCAl-associated BARDI gene, which encodes an associated and functionally similar protein which has interacting ability with pACC1 similar to the BRCT domain. The Danio rerio embryo develops under higher proliferation rate with low oxygen environment. Considering the above facts, we hypothesized that it may switch over to de novo lipogenesis similar to the cancer cells.

The survival rate decreased with high concentrations of PCN-J04 exposure due to pore size enlargement of chorion which might benefit the entry of larger amount of nano particles. Large dose of nanoparticles might drive toxic amounts of thermal energy which could lead to lethality. Further, the delay in hatching with higher concentration might be attributed to the hindrance in growth of gill filaments due to extreme starvation of nutrients (lipids). Furthermore, the nanoparticles that enter into the body might show cytotoxic and immunotoxic effects due to the distribution of the nanoparticles in the body. This might be similarly useful when tumor tissues are targeted. However, the heat shock proteins could be induced by PCN-J04 might potentially damage the cell by disturbing many cellular processes including protein synthesis, folding, translocation, and assembly of larger protein complexes, all of which could be impaired by stress. The tail deformity, pericardial edema, yolk sac edema and tissue ulceration (Fig. 8) were observed with increasing concentrations of PCN-J04 (Fig. 7c, d). This could be due to the absence of Elovl2 protein. The Elovl2 protein has vital functions such as fatty acid elongase and transferase activities (acyl group to amino-acyl). The regulation of Elovl2 depends on amount of fatty acids synthesis and BARD1 phosphorylation (Chen et al. 2013; Monroig et al. 2009). Thus, the authors have proposed a hypothesis that the action of pACC1 in regulating fatty acids biosynthesis might directly influence the level of Elovl2 expression in Danio rerio. The homeostasis in the expression of Elovl2 was maintained in 

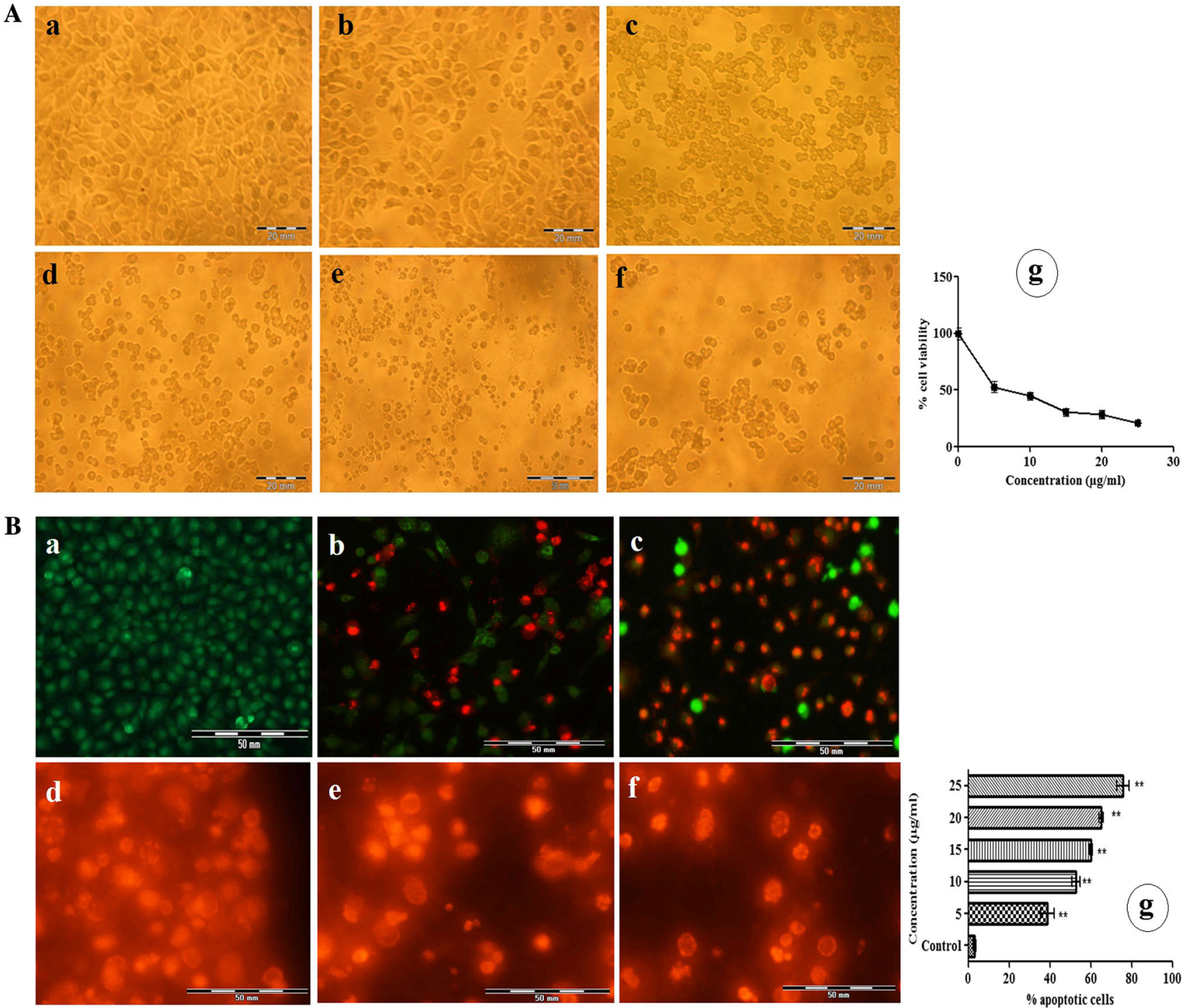

Fig. 9 A Influence of PCN-J04 in cell viability on MDA-MB-231 cell lines a control cells, b 5, c 10, d 15, e 20, f $25 \mu \mathrm{g} / \mathrm{ml}$ peptide final volume containing PCN-J04 treated and $\mathbf{g}$ represents Percentage viable cells; B PCN-J04 induced apoptosis on MDA-MB-231 cell

the lower levels of PCN-J04, but in higher concentration, the expression could be expected to be decreased.

The delayed action of PCN-J04 on Danio rerio might be due to sustained release of peptide. Further, lethality in higher concentration might be due to metabolic disturbances; in lower concentrations, auto correction might be achieved by embryos.

\section{Effect of PCN-J04 on cell viability}

The dose-dependent effect of PCN-J04 on cell proliferation was examined by the MTT assay. MTT is reduced by living cells and the resultant formazan product is proportional to lines a control cells, b 5 , c 10, d 15 , e 20 , f $25 \mu \mathrm{g} / \mathrm{ml}$ peptide final volume containing $\mathrm{PCN}-\mathrm{J} 04$ treated $\mathrm{g}$ represents percentage of apoptotic cells

the cell viability. The PCN-J04 treatment $(5,10,15,20$ and $25 \mu \mathrm{g} / \mathrm{mL}$ for $24 \mathrm{~h}$ ) on MDA-MB-231 cells induced a dosedependent cytotoxicity, with approximate $\mathrm{IC}_{50}$ value of $6.37 \mu \mathrm{g} / \mathrm{mL}$ (final concentration of peptide containing PCN-J04) [Fig. 9A (g)]. The percentage of viable cells treated with PCN-J04 significantly decreased when compared to control [Fig. 9A (a-f)]. Tandem repeats of BRCT domains can be found in BRCA1 and there is an option of minimal aggregation that would contribute to faster relaxation in the Free State, as in pACC1 peptide complexes BRCT domain. This amendment precisely correlated to our results in which $\mathrm{PCN}-\mathrm{J} 04$ possess the concentration dependent apoptotic effect in MDA-MB-231 cells. 


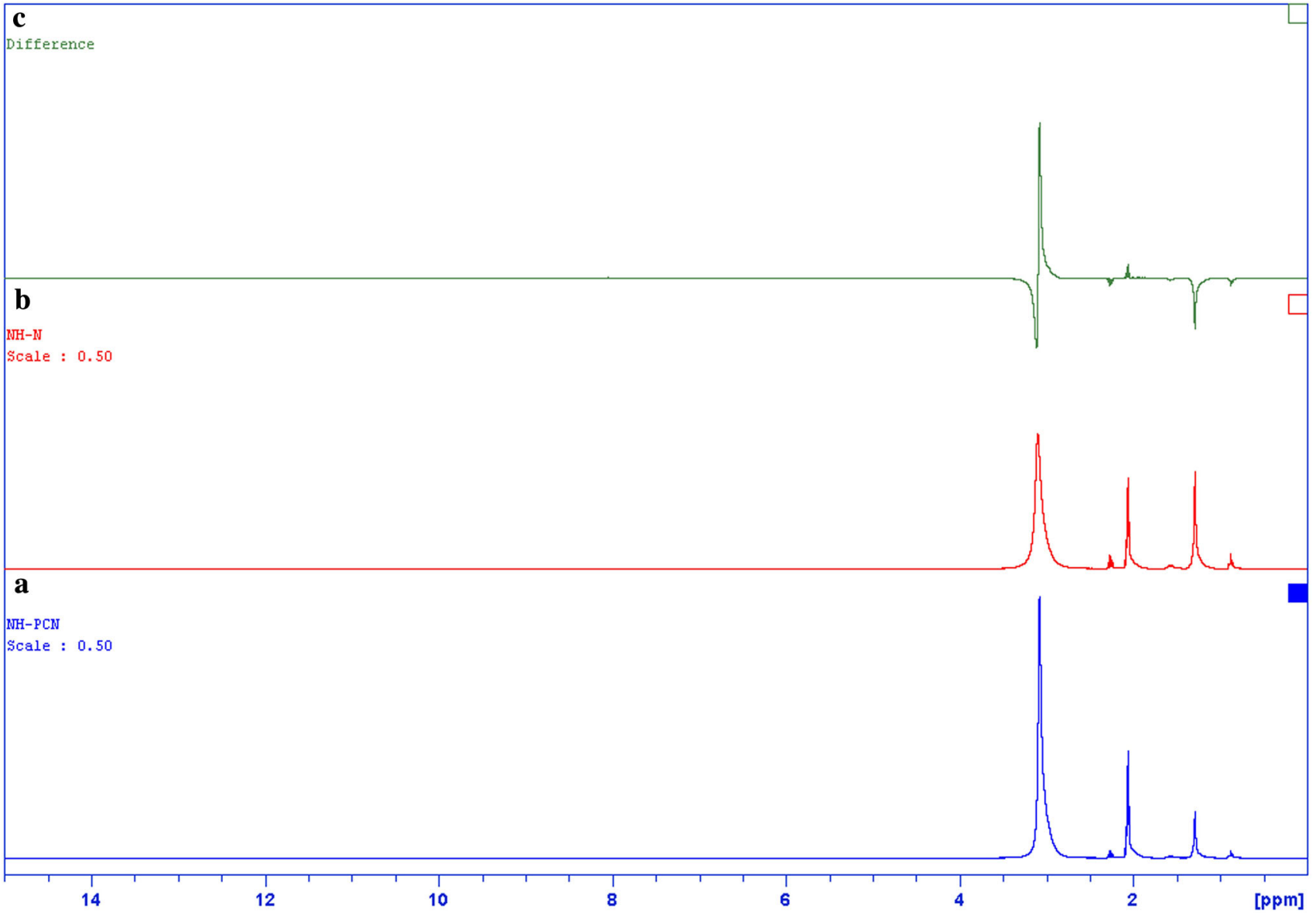

Fig. $10 \mathrm{H}^{1} \mathrm{NMR}$ spectra of lipids extracted from MDA-MB-231 cells a PCN-J04 treated cells lipids spectrum control cells lipids spectrum; b control cells lipids spectrum; c overlaid difference spectrum of $(\mathbf{a}, \mathbf{b})$

\section{Effect of PCN-J04 on apoptosis}

Dual staining (acridine orange/ethidium bromide) was used to evaluate the nuclear morphology including chromatin condensation around the nuclear membrane of apoptotic cells. The results discriminates yellow-early apoptosis and orange/red-late apoptosis observed with PCN-J04 treated cells [Fig. 9B (a-f)]. Whereas, uniform bright green live cells were seen in control. The percentage of apoptotic cells was high in $10 \mu \mathrm{g} / \mathrm{mL}$ [Fig. 9B (g)] final volumes of peptide containing PCN-J04.

\section{PCN-J04 on lipid levels}

The $\mathrm{H}^{1}$ NMR spectrum of control and PCN-J04 treated cellular lipids were shown in Fig. 10. The tiny peak at $0.9 \mathrm{ppm}$ belongs to $-\mathrm{CH} 3$ of palmitic acid which altered signals in PCN-J04 treated cellular lipid fractions, and there was no detectable acidic phospholipids signal in both spectra. The variation in the overlaid $\mathrm{H}^{1} \mathrm{NMR}$ spectra at $0.9 \mathrm{ppm}$ can perhaps be attributed to reduction in the palmitic acid contents in PCN-J04 treated cellular lipid fractions.

\section{Conclusion}

The present study outlines the pharmaceutical characters and biocompatible nature of pACC1 loaded chitosan nanoparticles. The sustained release ability of PCN-J04 will be highly appreciated with in vivo conditions. Further, it evidenced potent anti-tumorigenic effect on MDA-MB231 cells via lowering lipid levels. Hence, these nanoparticles perhaps recommended as adjuvant therapeutics while treating solid tumors.

Conflict of interest The authors report no conflicts of interest in this work.

Open Access This article is distributed under the terms of the Creative Commons Attribution 4.0 International License (http://creativecommons.org/licenses/by/4.0/), which permits unrestricted use, distribution, and reproduction in any medium, provided you give appropriate credit to the original author(s) and the source, provide a 
link to the Creative Commons license, and indicate if changes were made.

\section{References}

Azimi B, Nourpanah P, Rabiee M, Arbab S (2014) Producing gelatin nanoparticles as delivery system for bovine serum albumin. Iran Biomed J 18(1):34-40

Borghouts C, Kunz C, Groner B (2005) Current strategies for the development of peptide-based anti-cancer therapeutics. J Pept Sci 11(11):713-726

Brunet J, Vazquez-Martin A, Colomer R, Grana-Suarez B, MartinCastillo B, Menendez JA (2008) BRCA1 and acetyl-CoA carboxylase: the metabolic syndrome of breast cancer. Mol Carcinog 47(2):157-163

Catarina PR, Neufeld RJ, Antonio JR (2006) Design of insulin loaded alginate nanoparticles: influence of the calcium ion on polymer gel matrix properties. Chem Ind Chem Eng Quarter 12(1):47-52

Chen YS, Luo WI, Lee TL, YU SS, Chang CY (2013) Identification of the proteins required for the fatty acid desaturation in zebrafish (Danio rerio). Biochem Biophys Res Commun 440(4):671-676

Dash S, Murthy PN, Nath L, Chowdhury P (2010) Kinetic modeling on drug release from controlled drug delivery systems. Acta Pol Pharm 67(3):217-223

Erazo-Oliveras A, Muthukrishnan N, Baker R, Wang TY, Pellois JP (2012) Improving the endosomal escape of cell-penetrating peptides and their cargos: strategies and challenges. Pharmaceuticals (Basel) 5(11):1177-1209

Flory PJ (1953) Principles of polymer chemistry, 1st edn. United States, Ithaca

Folch J, Lees M, Sloane Stanley GH (1957) A simple method for the isolation and purification of total Lipids from animal tissues. J Biol Chem 226(1):497-509

Grant M, Leone-Bay A (2012) Peptide therapeutics: it's all in the delivery. Ther Deliv 3(8):981-996

Hu Y, Jiang X, Ding Y, Ge H, Yuan Y, Yang C (2002) Synthesis and characterization of chitosan-poly(acrylic acid) nanoparticles. Biomaterials 23(15):3193-3201

Jagatheesh K, Pavankumar P, Kowsalya R, Elangovan N (2014) Development and validation of an HPLC method for the quantification of an Anticancer Peptide. Chem Sci Trans 3(3): 1078-1082

Kasibhatla S, Amarante-Mendes GP, Finucane D, Brunner T, BossyWetzel E, Green DR (2006) Acridine orange/ethidium bromide (AO/EB) staining to detect apoptosis. CSH Proto. doi:10.1101/ pdb.prot4493

Katas H, Dzulkefli NNSN, Sahudin S (2012) Synthesis of a new potential conjugated TAT-Peptide-chitosan nanoparticles carrier via disulphide linkage. J Nanomater. doi:10.1155/2012/134607
Lagopati N, Tsilibary EP, Falaras P, Papazafiri P, Pavlatou EA, Kotsopoulou E, Kitsiou P (2014) Effect of nanostructured TiO2 crystal phase on photoinduced apoptosis of breast cancer epithelial cells. Int J Nanomed 9(1):3219-3230

Lin F, Suda J, Yeung A (2014) A small point regarding DLVO coagulation conditions. J Colloid Interface Sci 430:113-115

Ma Z, Yeoh HH, Lim LY (2002) Formulation pH modulates the interaction of insulin with chitosan nanoparticles. J Pharm Sci 91(6):1396-1404

Magnard C, Bachelier R, Vincent A, Jaquinod M, Kieffer S, Lenoir GM, Venezia ND (2002) BRCA1 interacts with acetyl-CoA carboxylase through its tandem of BRCT domains. Oncogene 21(44):6729-6739

Matsumura Y, Maeda H (1986) A new concept for macromolecular therapeutics in cancer chemotherapy: mechanism of tumoritropic accumulation of proteins and the antitumor agent smancs. Cancer Res 46(12 Pt 1):6387-6392

Monroig O, Rotllant J, Sánchez E, Cerdá-Reverter JM, Tocher DR (2009) Expression of long-chain polyunsaturated fatty acid (LCPUFA) biosynthesis genes during zebrafish Danio rerio early embryogenesis. Biochim Biophys Acta 1791(11):1093-1101

Narayanan D, Anitha A, Jayakumar R, Chennazhi KP (2013) In vitro and in vivo evaluation of osteophorosis therapeutic peptide PTH 1-34 loaded pegylated chitosan nanoparticles. Mol Pharm 10(11):4159-4167

Nesalin AJ, Smith JA (2012) Preparation and evaluation of chitosan nanoparticles containing zidovudine. Asian J Pharm Sci 7(1):80-84

Ofokansi K, Gerhard Winter G, Fricker G, Coester C (2010) Matrixloaded biodegradable gelatin nanoparticles as new approach to improve drug loading and delivery. Eur J Pharm Biopharm 76(1):1-9

Pooja D, Kulhari H, Singh MK, Mukherjee S, Rachamalla SS, Sistla R (2014) Dendrimer-TPGS mixed micelles for enhanced solubility and cellular toxicity of taxanes. Colloids Surf B Biointerfaces 121:461-468

Ray H, Moreau K, Dizin E, Callebaut I, Venezia ND (2006) ACCA phosphopeptide recognition by the BRCT repeats of BRCA1. J Mol Biol 359(4):973-982

Saeed M, Abbas ZM, Ali S (2013) Preparation and characterization of sodium alginate nanoparticles containing ICD-85 (venom derived peptides). Inter J Innov App Stud 4(3):534-542

Shen Y, Tong L (2008) Structural evidence for direct interactions between the BRCT domains of human BRCA1 and a phosphopeptide from human ACC1. Biochemistry 47(21):5767-5773

Singh AK (2005) Advanced X-ray techniques in research and industry (stand alone). IOSPress Richmond, TX

Zhu X, Zhu L, Duan Z, Qi R, Li Y, Lang Y (2008) Comparative toxicity of several metal oxide nanoparticle aqueous suspensions to Zebrafish (Danio rerio) early developmental stage. J Environ Sci Health A Tox Hazard Subst Environ Eng 43(3):278-284 